\title{
Number Sense Instruction: A Comprehensive Literature Review
}

\author{
Sheetal Sood ${ }^{1} \&$ Megan Mackey ${ }^{1, *}$ \\ ${ }^{1}$ Education Department, University of Hartford, West Hartford, CT 06117, USA \\ *Corresponding author: Education Department, University of Hartford, West Hartford, CT 06117, USA. E-mail: \\ mmackey@hartford.edu
}

Received: August 20, 2014

Accepted: October 7, $2014 \quad$ Online Published: October 11, 2014

doi:10.5430/wje.v4n5p58

URL: http://dx.doi.org/10.5430/wje.v4n5p58

\begin{abstract}
This article summarizes the findings of research studies focusing on number sense instruction to improve mathematics competence of school going children. Twenty-three studies were located that met the inclusion criteria. Interventions gleaned from the review were categorized based on type of instruction (i.e., constructivist, explicit or a combination of the two). Treatment outcomes are discussed in relation to the various instructional approaches, student characteristics (e.g., grade, age), instructional features (e.g., materials, treatment length), assessment (formal, informal) and methodological features. Implications for classroom practice and future research directions are provided.
\end{abstract}

Keywords: number sense; literature review; constructivist approach; explicit instruction

\section{Background}

A strong sense of number and the quantity it represents is an integral part of all areas of life affecting successful functioning on the job, in school, at home, and in the community. Despite the importance of quantitative reasoning, mathematical difficulties are widespread among U.S. students (Dougherty, 2003; Ostad, 1998). Results of national and international assessments indicate that many students from United Sates experience difficulties in the areas of mental computation, estimation, and quantitative judgment, all of which are important components of the understanding of number (Greeno, 1991; National Council of Teachers of Mathematics, [NCTM], 2000; Tsao, 2011).

Knowledge about the structure of the number system is essential for students to perform computations in flexible and creative ways. While a robust sense of number is a major component of the mathematics curriculum in elementary and middle school, number sense is also crucial for the development of later mathematical thinking (NCTM, 2000). Number sense entails knowledge of counting, number patterns, magnitude comparisons, estimation, and number transformation (Berch, 2005). Students with good number sense develop a quantitative intuition that helps them to solve problems in a flexible manner. They understand that numbers are representative of objects, magnitudes, relationships, and other attributes and are aware that numbers can be operated on, compared, and used for communication (Markovits \& Sowder, 1994; NCTM, 2000; National Research Council, 2001, Tsao, 2011).

Mathematical knowledge is comprised of procedural and conceptual knowledge (Miller \& Hudson, 2007). Traditionally, mathematics instruction has emphasized more basic skills (e.g., computation) instruction rather than higher order skills such as thinking, reasoning, and problem solving. Such a focus is viewed as being too narrow and likely to compartmentalize children's numerical thinking (Case, 1989). Because this approach encourages rote learning of procedural knowledge, which in turn may lead to a weak understanding of concepts, mathematics reform was called for. This reform led to a new way of conceptualizing the teaching and learning of mathematics. With the publication of the NCTM's Curriculum and Evaluation Standards for School Mathematics in 1989 and Principles and Standards for School Mathematics in 2000, the emphasis shifted from procedural knowledge and rote-driven computation to conceptual knowledge (Schoenfeld, 2002).

The notion of conceptual knowledge originated from the epistemological theory of constructivism. Constructivists hold the position that learners actively construct knowledge through their interactions in the world and efforts to make sense out of those experiences (Ultanir, 2012). This is contrary to the traditional view that knowledge exists independently, outside of the learner, and must be transmitted to (or imposed on) the learner. Constructivist 
classrooms provide a contrast to the traditional paradigm. Rather than asking students to memorize facts and repeat or replicate taught procedures, constructivist teaching practices are inquiry based and "help learners to internalize and reshape, or transform new information" (Brooks \& Brooks, 1993, p. 15). When theories of learning and instruction are considered, traditional interventions focus on teaching basic math facts and emphasize mastery of algorithms and repeated practice (Gersten \& Chard, 1999), with a focus on execution of procedural knowledge. Alternatively, conceptual interventions stress understanding of the principles that govern a domain and/or the interrelations between units of knowledge in a domain (Bisanz \& LeFevre, 1992).

Although the instructional principles and guidelines proposed by the NCTM (2000) have highlighted the importance of conceptual understanding of mathematics, mathematics instruction for struggling students has typically emphasized mastery of algorithms and repeated practice of routine procedures (Gersten \& Chard, 1999) and a superficial understanding of mathematics, rather than a deep appreciation of its structure and knowledge (Hiebert, 1986). Many educators and researchers agree that conceptual understanding can be realized with a balance of both teacher-directed instruction and child-centered, inquiry-based approaches (Sood \& Jitendra, 2013; National Research Council, 2001).

There is emerging evidence that number sense is one of the most important skills necessary for success with basic mathematical computations in the early grades (Chard et al. 2005; Gersten \& Chard, 1999). With well-developed number sense knowledge, students can use flexible ways to make mathematical judgments and develop useful strategies for solving complex problems (NCTM, 2000).

\subsection{Mathematical Knowledge: Learning and Instruction}

The theoretical framework for number sense instruction draws from reform-based approach and focuses on cognitively guided instruction. Over the past decade, several investigators have turned to the rich body of evidence that is available in cognitive science to obtain tools and insights to improve the teaching and learning of mathematics in early elementary years (Griffin \& Case, 1997; Montague, 1997; Resnik, Bill, \& Lesgold, 1990). The purpose of this article is to review and summarize the literature related to the use of validated mathematics practices with a focus on teaching number sense.

\section{Method}

In this study, we defined number sense interventions as instructional practices and activities designed to enhance the number sense achievement of students. We reviewed all studies published from 1975 to 2013 that focused on number sense interventions to improve mathematics proficiency of school-age children.

\subsection{Literature Search and Procedure}

First, we conducted a broad computerized search of the literature on number sense instruction using ERIC, PsychINFO, and Social Science Citation index databases from 1975-2013. Descriptors for the computerized searches included the following combinations: number sense; mathematics instruction, at-risk students, learning disabilities, explicit instruction, constructivist approach, number relationships. Second, we conducted an ancestral search of studies using the reference lists of identified articles. Finally, we hand-searched the following journals to locate the most recent literature: Journal of Learning Disabilities, Exceptional Children, Journal of Special Education, Learning Disability Quarterly, Learning Disabilities Research and Practice, and Remedial and Special Education, American Educational Research Journal, The Elementary School Journal, Journal of Research in Mathematics Education, School Science and Mathematics, Early Education and Development, Psychology of Mathematics Education, Journal of Educational Psychology, International Journal of Science and Mathematics Education, Early Childhood Research Quarterly.

The search resulted in 978 studies of which 55 studies were selected for further review based on analysis of the title, keywords and abstracts. Of these 55 studies, 23 (42\%) met our criteria for inclusion in this study. The review of identified articles was divided into two phases. First, the two authors determined if a study met the criteria for inclusion using a consensus model; any disagreements were reconciled. During the second phase, an independent evaluator examined 14 of the 23 studies (61\%). Inter-rater reliability based on whether to include the study was $92 \%$ (calculated by taking the number of agreements and dividing the number of agreements plus disagreements multiplied by 100).

\subsection{Criteria for Inclusion}

First, the study had to focus on number sense and had to include some form of an evaluation of the effectiveness of a 
well-defined method for improving mathematics proficiency. This could be done in a variety of ways: (a) specific teaching approaches were used to improve mathematics instruction (e.g., use of explicit instruction; constructivist approach), (b) specific focus on number sense of any mathematics concept. We did not include studies that focused on mathematics content other than number sense as defined by the researchers. Second, students in the study had to be school-age students irrespective of their ability levels. All students irrespective of their ability levels (identified with a disability, at-risk students, those identified as typically achieving) were included in the study. Third, studies included in the analysis had to include at least one measure of number sense; otherwise the study was excluded. Fourth, only studies published in English in peer reviewed journals or books were included. We did not explore other sources in the literature (e.g., Dissertation Abstracts) in a systematic manner or contact all active researchers in the area for unpublished studies. As such, this review may represent a potential bias toward published studies versus unpublished articles (Lipsey \& Wilson, 1993); thus, conclusions based on the review should be reviewed as tentative.

\section{Coding Procedures}

\subsection{Study Descriptions}

Studies that met the inclusionary criteria were coded on the following variables: (a) intervention type, (b) mathematical domain, (c) sample size, (d) grade level, (e) curriculum type, (f) teacher training, (g) assessment type, (h) design, and (i) results. In addition, we noted who implemented the intervention (i.e., the classroom teacher, other school personnel, or the researcher). A total of 23 studies met the criteria of inclusion in this synthesis. Interrater agreement on coding pertinent sample and study characteristics for each study was determined. The mean interrater agreement was $92 \%$ (range $=84 \%-100 \%$ ).

Table 1. Summary of Reviewed Studies

\begin{tabular}{|c|c|c|c|}
\hline Author & $\mathrm{N}$ & Grade & Design \\
\hline \multicolumn{4}{|c|}{ Constructivist Intervention } \\
\hline Markovits \& Sowder, 1988 & 20 & $4^{\text {th }} / 6^{\text {th }}$ & Control \\
\hline Fischer, 1990 & 86 & $\mathrm{~K}$ & Control \\
\hline Griffin, Case, \& Seigler, 1994 & $7-38$ & K & Control w/ Comparison \\
\hline Markovits \& Sowder, 1994 & 12 & 7 th & Control w/ Comparison \\
\hline Funkhouser, 1995 & 12 & Elem. & Case Study \\
\hline Griffin, Case, \& Capodilupo, 1997 & 60 & $\mathrm{~K}$ & Control \\
\hline Yang, 2002 & 29 & Middle & Control w/ Comparison \\
\hline Yang, 2003 & 75 & Elem. & Control w/ Comparison \\
\hline Starkey, Klein, \& Wakeley, 2004 & 163 & Pre-K & Control w/ Comparison \\
\hline Yang, Hsu, \& Huang, 2004 & 140 & $6^{\text {th }}$ & Control \\
\hline Young-Loveridge, 2004 & 106 & Pre-K & Control w/ Comparison \\
\hline Aunio, Hautamaki,\& Van Luit, 2005 & 45 & Pre-K & Control w/ Comparison \\
\hline Clements \& Sarama 2008 & 253 & Pre-K & Control \\
\hline Yang \& Wu, 2010 & 60 & $3^{\text {rd }}$ & Control \\
\hline Bryant et al. 2011 & 204 & $1^{\text {st }}$ & Control w/ Comparison \\
\hline Clements, Sarama, Spitler, Lange, \& Wolfe 2011 & 1375 & Pre-K & Control \\
\hline \multicolumn{4}{|c|}{ Explicit Instruction Intervention } \\
\hline Arnold, Fisher, Doctoroff, \& Dobbs, 2002 & 112 & Pre-K & Control w/ Comparison \\
\hline Chard et al., 2008 & 254 & $\mathrm{~K}$ & Control w/ Comparison \\
\hline Olson \& Foegen, 2009 & 13 & 1 st & Control w/ Comparison \\
\hline Clarke et al., 2011 & 1302 & $\mathrm{~K}$ & Control \\
\hline \multicolumn{4}{|c|}{ Combination Intervention } \\
\hline Sood \& Jitendra, 2013 & 101 & $\mathrm{~K}$ & Control w/ Comparison \\
\hline Dyson, Jordan, \& Glutting, 2013 & 121 & $\mathrm{~K}$ & Control \\
\hline Jordan, Glutting, Dyson, Hassinger-Das, \& Irwin 2012 & 132 & $\mathrm{~K}$ & Control \\
\hline
\end{tabular}




\section{Results}

\subsection{Explicit Instruction Interventions}

Arnold, Fisher, Doctoroff, and Dobbs (2002) implemented a classroom intervention designed to promote early math skills (e.g., counting, recognizing and writing numbers, etc.) of preschool students. Participants included 112 children from eight classrooms (6 half day and 2 full day classrooms) in two Head Start centers. Half and full-day students were paired and randomly assigned to either the intervention $(n=56)$ or control condition $(n=56)$. Results of the study indicated a significant increase in emergent math skills of students in the experimental group when compared to students in the control group. There was a substantively large and significant change in scores on the Test of Early Mathematics Ability - Second Edition (TEMA-2). While the experimental group improved their scores by 3.67 points, there was an improvement of only 0.84 points in the control group. This increase indicates that the experimental group learned four times more than the control group.

Chard et al. (2008), utilized a pre-post control group design to examine the feasibility of incorporating the Early Learning in Mathematics (ELM) Program into classroom practice. A total of 254 kindergarten students participated in the study, with a treatment group consisting of 186 students in 6 classrooms and a comparison group consisting of 102 students in 5 classrooms. The effect of the experimental curriculum was measured through standardized assessments. Results showed that students in ELM classrooms scored approximately 2.7 raw-score points higher on the Stanford Early School Achievement Test - Second Edition (SESAT-2) than students in the control classrooms. This difference was statistically significant with $a$ set at .10 . The effect of the ELM intervention did not show a difference for higher and lower scoring students.

Olson and Foegen (2009) examined the efficacy of small group teacher-developed (TD) interventions versus 3-Tier Mathematics Model (3TMM) interventions. A total of 13 first grade students participated in the study with 6 students receiving TD intervention and 7 receiving 3TMM intervention. There was no control group. Initial screening results revealed no significant difference between groups on the Number Identification, Quantity Discrimination, and Mixed Numeracy measures. However, students in the TD group scored significantly lower on the Missed Number task than students in the 3TMM group. When examining student growth, results showed significant improvement from beginning to end in students from both groups on both the Quantity Discrimination and Mixed Numeracy measures.

Clarke et al. (2011) used a randomized controlled trial to measure the impact of the ELM Program on the achievement of students at risk for mathematics difficulties. A total of 1,302 kindergarten students participated in the study with 660 learning the ELM curriculum and 553 learning the standard curriculum. Student performance was evaluated at pretest and posttest through the Early Numeracy-Curriculum Based Measurements (EN-CBM) which examined students' skills in oral counting, number identification, quantity discrimination, and missing number. The final measure used was the Test of Early Mathematics Ability - Third Edition (TEMA-3). Results indicated that for students not at risk for math difficulties, there was no statistically significant difference between students in ELM and control classrooms on TEMA or EN-CBM scores. However, there were statistically significant differences in gains for students at risk for math difficulties in ELM classrooms versus students in control classrooms on TEMA raw scores and EN-CBM total score. Furthermore, at-risk students in ELM classrooms made greater gains than not-at-risk students in ELM classrooms. Gain scores of at-risk treatment students were significantly greater than control peers, and greater than gains of not-at-risk peers, effectively reducing the achievement gap.

\subsection{Constructivist Interventions}

Markovits and Sowder (1988) investigated the effects of an instructional program that emphasized mental computation and how it could be enhanced by improved number sense. In this study, the authors deemed mental computation to be more than a series of skills to be mastered, but as higher order thinking involving the use of multiple strategies based on number and operation concepts. Participants included 10 fourth grade and 10 sixth grade average achieving students, who were encouraged to explore and use a variety of nonstandard strategies that focused on number relationships. Pretest to posttest interview results indicated that the proportion of both fourth and sixth grade students who used standard methods (e.g., paper-and-pencil algorithms, digits and rules) to solve problems decreased from $72.5 \%$ to $35 \%$. In contrast, the proportion of students who used nonstandard methods (e.g., understanding of numbers being processed, left to right procedures, and reformulation of numbers in the problem) increased substantially from $7.5 \%$ to $51.5 \%$. Further, results suggested that the use of non-standard methods correlated with a greater number of problems solved correctly. However, the statistical tests to assess significance were not reported. In addition, the mean time to solve problems using nonstandard methods decreased from $42 \mathrm{~s}$ to 19 s. This study provided initial evidence that nonstandard strategies not only helped students with their math computational skills in terms of an increase in the proportion of correct answers, but also served to simultaneously 
reduce the time taken to solve computational problems.

Fischer (1990) used a pretest-posttest control group design to examine the effectiveness of curricula that concentrated on the cardinal component of number. Participants included 86 kindergarten students broken into one treatment group $(\mathrm{n}=42)$ and one control group $(\mathrm{n}=44)$. In lieu of random assignment of subjects to treatment groups, existing classes were used. Students in the intervention group were taught using a part-part-whole curriculum, while students in the control group were taught using a count/say/write curriculum. Results revealed significant main effects for each test with students who learned using the part-part-whole curriculum as they gained more on the average than students taught using the count/say/write curriculum.

Griffin, Case, and Siegler (1994) focused on number sense development among younger students. They conducted a series of five studies over three years that investigated the effectiveness of the Rightstart program. The major purpose of these studies was to investigate whether children's development of number sense would enhance their conceptual understanding of addition and subtraction using a pretest-posttest control group design. Participants included kindergarten students at risk for mathematics difficulties ( $N=7$ to 38$)$.

Results of all five studies indicated that students who completed the Rightstart program showed significant gains in number sense compared to students in the control groups. Further, transfer test results indicated that the majority of students in the treatment group were able to successfully complete four of the five transfer tasks; whereas, those in the control group did not complete the five tasks successfully. In addition, results of the Number Knowledge Test, readministered one year later, indicated that all students who had received the Rightstart program in kindergarten passed level 1 of this test (versus $87 \%$ of the students passing one year earlier). Interestingly, although $83 \%$ of the students in the control group also demonstrated this knowledge (compared to $25 \%$ of students passing one year earlier), students in the treatment group further demonstrated the ability to solve double-digit problems that were tested in level 2 of the Number Knowledge Test. Also, student performance on the first-grade arithmetic test indicated that the majority of treatment group students passed the oral arithmetic and the word problem tests, whereas a large proportion of control group students failed these tests.

Markovits and Sowder (1994) extended their previous research on number sense to seventh-grade students by focusing on number magnitude, mental computation, and mental estimation (including decimals and fractions). Participants included 12 seventh-grade average-achieving students attending a pre-algebra class. Based on student performance on written measures and interviews, posttest and retention test scores were higher than pretest scores. Results suggested that students were more likely to use strategies that reflected number sense following the intervention, and they continued to use these strategies six months after completion of the instructional units.

In 1996, Funkhouser investigated the effectiveness of procedures designed to develop number sense and basic computational skills. Participants $(N=12)$ were kindergarten- grade 1 students diagnosed with learning disabilities who demonstrated disorders in one or more of the basic psychological processes involved in understanding spoken or written language. Results of the study indicated that students were able to use the five and ten frames with $90 \%$ accuracy, thereby indicating mastery of addition facts.

Griffin, Case, and Capodilupo (1997) conducted two additional studies on number sense. The first study investigated the theoretical implications of the Rightstart program's foundation. Rightstart was implemented in three kindergarten classrooms $(N=60)$ serving families who had migrated from rural Portugal to Toronto. The study included three groups: (1) a treatment group, (2) a traditional math group, and (3) a reading readiness group. To enhance comparability across conditions, the instructional modules were identical in length and comparable in format. Posttests and transfer tests on number knowledge were conducted to measure the effectiveness of the curriculum. Results indicated that $80 \%$ of the students who received instruction based on the Rightstart program performed at first grade level, whereas only $35 \%-37 \%$ of the students in the control groups (i.e., traditional math and reading readiness) demonstrated mastery. In addition, the majority of the students in the experimental group passed the transfer test at the first grade-level, when compared to students in the two control groups.

In the second study, Griffin et al. (1997) aimed to assess the potential of the Rightstart program for students in the United States. Participants included 55 kindergarten students from three inner-city schools in Massachusetts and consisted of minority students (i.e., Blacks, Hispanics, and Southeast Asians) from low to middle-low socio economic income status (SES) families. In addition, 19 students from the San Francisco Bay area were randomly selected to evaluate the effectiveness of the program in other regions of the United States. Similar to the previous study conducted in Toronto, a rank ordering procedure based on pretest results (Number Knowledge Test) was used to assign children to treatment (Rightstart program) and control group (no treatment). The resulting groups consisted of 24 children in the control group and 23 children in the experimental group. Results indicated that $87 \%$ of the 
students in the experimental group and $25 \%$ of the students in the control group performed at mastery level. Data from these two studies clearly indicate the need for a conceptually based readiness training program for children from varied cultural backgrounds. In addition, the Rightstart program was found to give students a conceptual structure that enhanced their ability to benefit from formal mathematics instruction in first grade.

Yang (2002) conducted an observational study that examined the importance of class discourse in promoting number sense. Participants included 29 sixth-grade students in Taiwan. In this study, the teacher divided the class into five groups and presented them with a challenging problem that required students to determine whether $3 / 8$ or $7 / 13$ is closer to $1 / 2$ (Markovits \& Sowder, 1994). Students were first required to discuss the problem within their groups and then share their responses with the entire class. Results indicated that students' performance improved after group work and discussion and understanding was retained six months after instruction was completed.

Another study by Yang (2003) investigated the extent to which number sense could be enhanced by adopting appropriate teaching techniques. Participants included 75 students from two fifth grade classrooms at a public school in Taiwan. Students in the two classrooms were assigned to either the experimental $(n=37)$ or the control group $(n=$ 38). Further, based on pretest results, students in each classroom were divided into high (top 10\%), middle (40\%-60\%), and low (bottom 10\%) achieving groups, with 12 students at each performance level in both conditions. In addition, two students were randomly selected from each level and interviewed before and after intervention, and then again four months later. Results suggested statistically significant differences between pretest, posttest, and retention test scores for both groups. While the scores for the experimental group increased by $44 \%$ (i.e. mean score increased from 12.35 to 17.81 ) after instruction, the scores for the control group increased only by $10 \%$ (i.e., mean score increased from 11.29 to 12.42 ).

Starkey, Klien, and Wakeley (2004) implemented a pre-kindergarten mathematics intervention in public and private preschools serving low- and middle-income families. A pretest-intervention-posttest design was adopted to determine the effectiveness of the designed curriculum that focused on enumeration and number sense. In addition to the investigator designed curriculum two commercially available computer-based math curricula were used. Results of the study indicated that children from middle-income families developed more mathematical knowledge than children from low-income families. They also showed an increase in students' composite scores and scores on individual tasks. Students also showed developmental advancements in the types of errors they made on problems presented.

Yang, Hsu, and Huang (2004) examined the effectiveness of an investigator designed mathematics curriculum. Overall results of the study demonstrated that the teaching of number sense activities is effective and helpful in developing children's number sense knowledge. Furthermore, the results of retention demonstrated that the students' learning is meaningful and significant. In summary the results of this study confirm the conclusions drawn from earlier studies (Markovits \& Sowder, 1994; Yang, 2003) that children's number sense can be promoted through well-designed activities and healthy learning environments.

Young-Loveridge (2004) conducted another study with preschool students to investigate the effectiveness of a program designed to improve the number skills (e.g., sequence of number words in order, numerals, etc.) of 5-year old children. Participants included 106 students from four schools in New Zealand. While students from two schools received the intervention, two schools served as the control schools. In addition, students' within each of the intervention schools were randomly assigned to either the intervention or the control group. Students in the experimental group $(n=23)$ received instruction in pairs for $30 \mathrm{~min}$ a day for a duration of 7 weeks. On the immediate posttest, students in the experimental group had significantly higher scores than students in the control group. However, differences between the groups were not maintained on posttest 2 and posttest 3 measures that were conducted six months and 15 months after the intervention.

Aunio, Hautamaki, and Van Luit (2005) investigated the effectiveness of number sense instruction using a pretest-posttest design. Participants included 45 preschoolers from a metropolitan area of Helsinki (Finland), who were randomly assigned to experimental $(n=22)$ and control groups $(n=23)$. Based on performance on the Early Numeracy Test (ENT) (Van Luit, J.E.H., Van de Rijt, B.A.M., \& Aunio, P., 2003), 12 of the 45 students were identified as having low number sense. Five of these students were in the experimental group and seven students were in the control group. Results indicated that the differences between the experimental and control groups were not statistically significant at pretest. On the immediate posttest, students in the experimental group had significantly higher scores on both relational and counting scales than students in the control group. However, the differences between the groups were not maintained on the follow-up measures that were conducted six months after the intervention. 
Clements and Sarama (2008) utilized a pre-post randomized trial design to evaluate the effectiveness of a preschool math program. Participants in 36 classrooms were broken up into experimental (Building Blocks), comparison, or control classrooms. A total of 36 teachers and 253 children were involved. Student achievement levels on the Early Mathematics Assessment (EMA) indicated that both intervention groups significantly outperformed the control group. The Building Blocks group significantly outperformed the comparison group and the comparison curriculum significantly outperformed the control group.

Yang and $\mathrm{Wu}$ (2010) investigated the effectiveness of a number program using a mixed methods approach. Quantitative methods were used to analyze the data of the pretest, post I test, and post II test between the experimental and the control groups. Qualitative methods were used to transcribe information from interviews and selected video segments that were collected as part of the intervention. Participants included students from two third grade classrooms in northern Taiwan. A total of 60 students were randomly assigned to experimental $(\mathrm{n}=30)$ and control $(n=30)$ groups. Results indicated that Taiwanese third grade students in the experimental group performed significantly better in number sense tests after the Unit I and Unit II compared with students in the control group.

Bryant et al. (2011) used a pre-post control design to examine the effects of an early numeracy preventative intervention. Participants included 204 first-grade students (139 treatment and 65 control) who had been deemed "at-risk" based on their performance on a progress monitoring measure. Intervention effects were measured through progress monitoring and standardized assessment measures. Results showed no significant differences between participants in the Texas Early Mathematics Inventory - Progress Monitoring (TEMI-PM) and Texas Early Mathematics Inventory - Outcome (TEMI-O) pretest measure. Posttest results indicate significant differences in favor of the intervention group for the Additional and Subtraction Combinations, Place Value, Number Sequences, and the TEMI-PM Total Score. No significant difference was found on the Magnitude Comparisons subtest. There was a statistically significant difference found for the TEMI-O Computation subtest. There was also no statistically significant difference on the SAT-10 Total Score.

Clements, Sarama, Spitler, Lange, and Wolfe (2011) employed a multi-site cluster randomized trial experimental design to evaluate the effectiveness of a research-based math program for young children. There were 106 classrooms and 42 schools in low-resource communities involved in the study. A total of 1,375 preschool children participated in the research, with 927 in experimental classrooms and 378 in control classrooms. Children in the experimental groups outperformed children in control groups on all EMA subtests and almost all individual test items. Furthermore, students in the experimental classes outperformed those in the control group on the total mathematics score.

\subsection{Combination of Explicit Instruction and Constructivist Intervention}

Sood and Jitendra (2013) investigated the effectiveness of a number sense program using a pretest-posttest-delayed posttest design. Participants included 101 kindergarten students (not-at-risk: 22 control and 36 experimental; at-risk: 18 control and 25 experimental) from five classrooms in a high-poverty elementary school. Using a quasi-experimental design, classrooms were randomly assigned to either the intervention (number sense instruction, NSI) or control group (general classroom instruction GCI). Results of the study indicated that students in the NSI condition outperformed students in the control condition on all number-sense-related measures and a few Early Numeracy-CBMs. In addition, the positive effects of NSI were retained 3 weeks after the intervention. Furthermore, results suggested that students not at risk for MD scored higher than students at risk for MD on benchmarks and nonverbal calculation but not on spatial relationships and more and less relationships.

Dyson, Jordan, and Glutting (2013) used a pretest, posttest, and delayed posttest design to examine the effectiveness of an 8-week number sense intervention for 121 kindergarten children in five schools serving high-risk children from low-income urban families. Participants were randomly assigned to the intervention or "business as usual" control group. The intervention consisted of small-group, 30-min sessions, 3 days per week, for a total of 24 sessions and targeted whole number concepts related to counting, comparing, and manipulating sets. Results indicate that the intervention group, when compared to the control group, made meaningful gains in early numeracy on the posttest and delayed posttest, and on a standardized test of calculation at immediate posttest.

Jordan, Glutting, Dyson, Hassinger-Das, and Irwin (2012) examined the impact of targeted small group number-sense intervention on high-risk kindergarteners from low-income communities. A total of 132 students were randomly assigned to either a number sense intervention group, language intervention group, or the business as usual control group. The number sense intervention consisted of 24 lessons that were implemented three times a week for 30 minutes by trained graduate students. The curriculum focused on number recognition and base 10 principles, number sequencing, verbal subitizing, written number activities, part-whole relationship, and problem solving 
operations. Results of the study indicated that while all students participating in the study showed improvement in number skills, students in the number sense intervention group out performed students in the other groups. In addition, results of the delayed posttest indicated that students in the intervention group retained the skills 8 weeks after intervention.

\section{Discussion}

A total of 23 studies were examined for this literature review. One study was published between 1980-1989, five studies between 1990-1999, and 17 studies between 2000-2013. The studies were categorized based on instructional type; four studies utilized explicit instruction, 16 studies followed a constructivist approach, three studies combined the explicit and constructivist approaches, and one study incorporated computer software. The vast majority, 20 studies, had the general education teacher implement the intervention, two studies used trained graduate students, while one study used a teacher that was not associated with the school. A total of 20 studies involved interventions that were conducted in the general education classroom, two studies were conducted in the classroom and hallway, and one study was carried out in a quiet, separate classroom. Ten studies utilized small group instruction, 12 studies involved whole group, and one study used a combined approach. Six of the studies involved research in pre-school settings, 9 in kindergarten classrooms, three in grades 1 through 5, and five in grades 6 through 8 . Nineteen studies assigned participants randomly. Ten studies measured treatment fidelity. None of the studies identified the intelligence quotient (IQ) of its participants.

The findings of this review on number sense interventions have several instructional implications for promoting quantitative literacy. Even though current research findings suggest that both procedural and constructivist interventions are equally important to promote competence in a domain, only three (13\%) out of 23 studies included in this review adopted this approach. Since explicit and constructivist interventions lie at two ends of the continuum of learning and instruction, it is essential to develop interventions that support both procedural and conceptual knowledge. This is important because procedural knowledge can serve to support conceptual knowledge, which is crucial for generation of appropriate procedures.

In addition two studies looked at the impact of number sense instruction on mathematics competence of students at risk for mathematics difficulties. Given that over $6 \%$ of school aged children in America face some form of mathematics difficulty, it is crucial to determine if number sense instruction would help students at risk for mathematics disabilities meet the standards of mathematical proficiency.

In summary, future research on mathematics instruction should investigate the impact validated number sense instruction on mathematics competence of student across grade levels and abilities.

\section{References}

Arnold, D.H., Fisher, P.H., Doctoroff, G.L., \& Dobbs, J. (2002). Accelerating math development in head start classrooms. Journal of Educational Psychology, 94(4), 762-770. http://dx.doi.org/10.1037/0022-0663.94.4.762

Aunio, P., Hautamaki, J., \& Van Luit, J. E. H. (2005). Mathematical thinking intervention programmes for preschool children with normal and low number sense. European Journal of Special Needs Education, 20(2), 131-146. http://dx.doi.org/10.1080/08856250500055578

Berch, D. B. (2005). Making sense of number sense: Implications for children with mathematical disabilities. Journal of Learning Disabilities, 38(4), 333-339. http://dx.doi.org/10.1177/00222194050380040901

Bisanz, J., \& LeFevre, J. (1992). Understanding elementary mathematics. In J. Campbell (Ed.), The nature and origins of mathematical skills(pp. 113-136). Amsterdam: North Holland, Elsevier Science Publishers.

Brooks, J. G., \& Brooks, B. G. (1993). The case for constructivist classrooms. Alexandria, VI: Association for Supervision and Curriculum Development.

Bryant, D. P., Bryant, B. R., Roberts, G., Vaughn, S., Pfannenstiel, K. H., Porterfield, J., \& Gersten, R. (2011). Early numeracy intervention program for first-grade students with mathematics difficulties. Exceptional Children, $78(1), 7-23$.

Case, R. (1989). Fostering the development of children's number sense. In J.T. Sowder \& B.P. Schapelle (Eds)., Establishing foundations for research on number sense and related topics: Report of a conference (pp. 57-64). San Diego State University Center for Research in Mathematics and Science Education. 
Chard, D. J., Clarke, B., Baker, S., Otterstedt, J., Braun, D., \& Katz, R. (2005). Using measures of number sense to screen for difficulties in mathematics: Preliminary findings. Assessment Issues in Special Education, 30(2), $3-14$.

Chard, D.J., Baker, S.K., Clarke, B., Jungjohann, K., Davis, K., \& Smolkowski, K. (2008). Preventing early mathematics difficulties: The feasibility of rigorous kindergarten mathematics curriculum. Learning Disability Quarterly, 31(1), 11-20.

Clarke, B., Smolkowski, K., Baker, S. K., Hank, F., Doabler, C. T., \& Chard, D. J. (2011). The impact of a comprehensive Tier I core kindergarten program on the achievement of students at risk in mathematics. Elementary School Journal, 111, 561-584. http://dx.doi.org/10.1086/659033

Clements, D. H., \& Sarama, J. (2008). Experimental evaluation of the effects of a research-based preschool mathematics curriculum. American Education Research Journal, 45, 443-494. http://dx.doi.org/10.3102/0002831207312908

Clements, D. H., Sarama, J., Spitler, M. E., Lange, A. A., \& Wolfe, C. B. (2011). Mathematics learned by young children in an intervention based on learning trajectories: A large-scale cluster randomized trial. Journal for Research in Mathematics Education, 42, 127-166.

Dougherty, C. (2003). Numeracy, literacy and earnings: Evidence from the national longitudinal survey of youth. Economics of Education Review, 22, 511-521. http://dx.doi.org/10.1016/S0272-7757(03)00040-2

Dyson, N. I., Jordan, N. C., \& Glutting, J. (2013). A number sense intervention for low-income kindergartners at risk for mathematics difficulties. Journal of Learning Disabilities, 46(2), 166-181. http://dx.doi.org/10.1177/0022219411410233

Fischer, F. (1990). A part-part-whole curriculum for teaching number in the kindergarten. Journal for Research in Mathematics Education, 21, 207-215. http://dx.doi.org/10.2307/749374

Funkhouser, C. (1995). Developing number sense and basic computational skills in students with special needs. School Science and Mathematics, 95(5), 236-239. http://dx.doi.org/10.1111/j.1949-8594.1995.tb15773.x

Gersten, R., \& Chard, D. (1999). Number sense: Rethinking arithmetic instruction for students with mathematical disabilities. The Journal of Special Education, 33(1), 18-28. http://dx.doi.org/10.1177/002246699903300102

Greeno, J. G. (1991). Number sense as situated knowing in a conceptual domain. Journal for Research in Mathematics, 22(3), 170-218. http://dx.doi.org/10.2307/749074

Griffin, S., \& Case, R. (1997). Re-thinking the primary school curriculum: An approach based on cognitive science. Issues in Education, 3(1), 1-49.

Griffin, S., Case, R., \& Capodilupo, A. (1997). Teaching for understanding: The importance of central conceptual structures in the elementary mathematics curriculum. In A. McKeough, I. Lupert, and A. Marini (Eds.), Teaching for transfer: Fostering generalization in learning (pp. 121-151). Hillsdale, NJ: Erlbaum.

Griffin, S., Case, R., \& Sielger, R. (1994). Rightstart providing the central conceptual prerequisites for first formal learning of arithmetic to students at risk for school failure. In K., McGilly, Classroom lessons integrating cognitive theory in classroom practice (pp 24-29). Cambridge, MA: MIT Press.

Hiebert, J. (1986). Conceptual and procedural knowledge: The case of mathematics. Hillsdale, NJ: Lawrence Erlbaum.

Jordan, N. C., Glutting, J., Dyson, N., Hassinger-Das, B., \& Irwin, C. (2012). Building kindergartners' number sense: A randomized controlled study. Journal of Educational Psychology, $104(3), 647$. http://dx.doi.org/10.1037/a0029018

Lipsey, M.W., \& Wilson, D.B. (1993). The efficacy of psychological, educational, and behavioral treatment: Confirmation from meta-analysis. American Psychologist, $50(2), \quad 113-115$. http://dx.doi.org/10.1037/0003-066X.50.2.113

Markovits, Z., \& Sowder, J. (1988). Mental computation and number sense. In M.J. Behr, C.B. Lacampagne, \& M.M. Wheeler (Eds.), Proceedings of the Tenth Annual Meeting of the North American Chapter of the International Group for the Psychology of Mathematics Education (pp. 58-64). DeKalb, IL.

Markovits, Z., \& Sowder, J. (1994). Developing number sense: An intervention study in grade 7. Journal for Research in Mathematics Education, 25(1), 4-29. http://dx.doi.org/10.2307/749290 
Miller, S., \& Hudson, P.J. (2007). Using evidence-based practices to building mathematics competence related to conceptual, procedural, and declarative knowledge. Learning Disabilities Research \& Practice, 22(1), 47-57. http://dx.doi.org/10.1111/j.1540-5826.2007.00230.x

Montague, M. (1997). Cognitive strategy instruction in mathematics for students with learning disabilities. Journal of Learning Disabilities, 30, 164-177. http://dx.doi.org/10.1177/002221949703000204

National Council of Teachers of Mathematics (2000). The curriculum and evaluation standards for school mathematics. Reston, VA

National Research Council (2001). Adding it up: Helping children learn mathematics. In J. Kilpatrick, J. Swafford, and B. Findell (Eds.), Mathematics Learning Study Committee, Center for Education, Division of Behavioral and Social Sciences and Education. Washington, DC: National Academy Press.

Olson, J., \& Foegen A. (2009). Exploring the use of early numeracy indicators for progress monitoring. Research Institute on Progress Monitoring (Technical Report No. 33). Minnesota: University of Minnesota.

Ostad, S.A. (1998). Developmental differences in solving simple arithmetic word problems and simple number-fact problems: A comparison of mathematically normal and mathematically disabled children. Mathematical Cognition, 4(1), 1-19. http://dx.doi.org/10.1080/135467998387389

Resnik, L. B., Bill, V., \& Legold, S. (1990). Developing thinking abilities in arithmetic class. In A. Demetriou, M. Shayer, \& A. Afklides (Eds.). The modern theories of cognitive development go to school. London: Routledge.

Schoenfeld, A. H. (2002). Making mathematics work for all children: Issues of standards, testing, and equity. Educational Researcher, 31(1), 13-25. http://dx.doi.org/10.3102/0013189X031001013

Sood, S., \& Jitendra, A.K. (2013). An exploratory study of a number sense program to develop kindergarten students' number proficiency. Journal of Learning Disabilities, 46(4), 328-346. http://dx.doi.org/10.1177/0022219411422380

Starkey, P., Klein, A., \& Wakeley, A. (2004). Enhancing young children's mathematical knowledge through a pre-kindergarten mathematics intervention. Early Childhood Research Quarterly, 19, 99-120. http://dx.doi.org/10.1016/j.ecresq.2004.01.002

Tsao, Y.L. (2011), Teaching children mathematics, The Journal of Mathematics Learning and Research, 11, 36.

Ultanir, E. (2012). An epistemological glance at the constructivist approach: Constructivist learning in Dewey, Piaget, and Montessori. International Journal of Instruction, 5(2), 195-212.

Van Luit, J.E.H., Van de Rijt, B.A.M., \& Aunio, P. (2003). Early numeracy test, Finnish Edition [Lukukasitetesti] (Helsinki, Psykologien kustannus).

Yang, D. C. (2002). Teaching and learning number sense. School Science and Mathematics, 102(4), 152-157. http://dx.doi.org/10.1111/j.1949-8594.2002.tb18197.x

Yang, D.C. (2003). Teaching and learning number sense: An intervention study of fifth grade students in Taiwan. International Journal of Science and Mathematics Education, 1, 115-134. http://dx.doi.org/10.1023/A:1026164808929

Yang, D. C., Hsu, C. J., \& Huang, M. C. (2004). A study of teaching and learning number sense for sixth grade students in Taiwan. International Journal of Science and Mathematics Education, 2(3), 407-430. http://dx.doi.org/10.1007/s10763-004-6486-9

Yang, D. C., \& Wu, W. R. (2010). The study of number sense: Realistic activities integrated into third-grade math classes in Taiwan. Journal of Educational Research, 103, 379-392. http://dx.doi.org/10.1080/00220670903383010

Young-Loveridge, J.M. (2004). Effects on early numeracy of a program using number books and games. Early Childhood Research Quarterly, 19, 82-98. http://dx.doi.org/10.1016/j.ecresq.2004.01.001 